\title{
Brittle books in our nation's libraries
}

\author{
By David C. Weber \\ Director, University Libraries \\ Stanford University
}

\section{The statement submitted by ARL and ALA before the Subcommittee on Postsecondary Education, Committee on Education and Labor, U.S. House of Representatives,} March 3, 1987.

I am David C. Weber, director of the Stanford University Libraries, member of the Association of Research Libraries and chair of its Committee on Preservation of Research Library Materials, also a member of the American Library Association and past president of its Association of College and Research Libraries.

While you have heard of the frightful rate at which valuable cultural records are becoming embrittled, this "brittle books" challenge must be faced and corrections made over the next two to three decades or we all shall have lost a good deal of who and what we are.

To put it in a local context, I shall describe the situation in my home town, Palo Alto, California-a city of some 60,000 people, including many scientists, engineers, teachers, government officials, students and writers.

An individual interested in a current political issue and concerned with its antecedents, causes, and past corrective attempts has available the following:

- A fine public library with over 230,000 volumes.

- The nearby Stanford University Libraries and the Hoover Institution, together having 5.5 million volumes, also nearly 3 million microtext sheets and large numbers of maps, motion picture films, pho- tographs, prints, slides, sound recordings and data sets.

- And within 20 miles there are a state university library, two private college libraries, four community college libraries, and a dozen other public libraries linked by a State Library inter-system service.

A richness for that individual pursuing a political issue? Yes and no.

The resources for study are, at 6 million volumes and upwards of 60 million manuscripts, far greater than in most communities for 60,000 people. The Hoover Institution alone has more archival records of social action than many entire states. However, over a quarter of these resources are now so fragile that use is perilous, and in little more than a decade any use will be problematic due to the rapid decay of paper. Most of those resources are housed in quarters where temperatures bake the materials several months of the year, a situation gradually being corrected at Stanford and elsewhere.

Resources in the West amount to only a fraction of what they are in the East and Northeast, even the Midwest. The hinterlands are in fact most of these United States. Requests for interlibrary loan increasingly result in no availability because the owning library indicates its book is too fragile to loan, and a microfilm does not exist, or by policy 
original letters and archival documents do not circulate outside the building, and again no film copy exists.

How frustrating for the individual researcher! How limiting if one does not live in Washington, New York, Philadelphia, or Boston! How frightening to realize that the condition is nationwide, of awesome proportions, and getting worse every year!

Concerning interlibrary loan of microfilms, there is a significant traffic of this type, though it is much less than of books or photocopies provided in lieu of the volume. An institution like Stanford University lends to all kinds of libraries-public and school libraries, county and state libraries, agencies of government, commercial and not-forprofit research organizations, as well as community colleges, four-year colleges and universities. In a recent year, Stanford has lent microfilms to institutions as far away as the State University of New York at Buffalo, Columbia, Florida, Johns Hopkins, Princeton, Rutgers, Virginia, and Yale. Libraries are experienced in lending this type of material. All academic and most public libraries have reading machines available for $35 \mathrm{~mm}$ film. Pre-filming activities, including collation and creation of film captions (targets), and technical specifications for filming, including quality control procedures, have been well established by national and international professional and standards organizations, with major contributions over the past 40 years by the Library of Congress.

The production of preservation microfilms is, in fact, one of long standing. Starting in the early 1930s there have been programs in some university libraries, and other research libraries such as the New York Public Library, to make archival master film copies of brittle material, copies from which public reading copies are made, thereby archivally assuring availability of the original text for future generations.

This preservation filming, sometimes the byproduct of an interlibrary loan request, is in the interest of the nation as a whole. It is true that the institution making the negative film is protecting its own investment in the original. But it is every bit as important to readers, students and scholars elsewhere throughout the country that the content be archivally preserved. Otherwise it may be lost ...permanently.

Let me use one example. In the early 1950s at the Harvard University Library, I was responsible for a foreign newspaper microfilm project that had been originated in 1938 with Rockefeller Foundation funds. One of the challenges that was undertaken was to prepare a complete master microfilm of every issue of Pravda and Izvestia. The first of these Russian newspapers began publishing March 18, 1917, and the second on February 28, 1917. The task was to complete the file for the first 20 years. This required obtaining negative film from copies of individual issues held at Columbia, the
New York Public Library, the Hoover Institution, Harvard, the British Museum Library, the Bibliothèque Nationale, the Bibliothèque de Documentation Internationale Contemporaine in Paris, and a few issues found only in Moscow itself. Even so, the master archival film still lacked 24 issues from 1917, nine in 1918, one in 1919, four in 1920, and one in 1921.

One can reflect, however, on how important was that preservation effort, as just one example of this ubiquitous "brittle books" problem. Copies of that film have now been sold to many libraries here and abroad. It is the only nearly complete record of these primary sources, regardless of where in the world an individual may be working.

Brittle books reside in libraries of all sizes and types. How any one library addresses the brittle book problem depends on a number of factors including but not limited to the number of brittle books to be treated, the filming and processing equipment, trained staff, and financial support available to the library. There is general agreement within the library community that it is unrealistic for every library to develop in-house facilities capable of producing archival-quality microfilming of brittle books. Reformatting is an expensive undertaking and in-house facilities are difficult to justify unless a library anticipates a significant volume and steady flow of brittle books to be treated. While there are a few exceptions, only the larger libraries have developed in-house programs to treat brittle books. Such operations serve their own institutional needs as well as serving the needs of other libraries as a source of microfilm to replace brittle books. Libraries without in-house preservation facilities, with just as serious a problem but with fewer numbers of brittle books, face an extra hurdle of identifying a laboratory or service agency where their unique materials may be treated.

Smaller libraries facing this special problem might take a number of different approaches. In some cases, a nearby library that has developed an in-house facility might provide preservation services for other libraries. A few commercial firms can handle archival microfilming. In addition, regional non-profit preservation laboratories have been established as cooperative and "mutual help" projects. One regional center is the Northeast Document Conservation Center (NEDCC) in Andover, Massachusetts; developed with funds from the Council on Library Resources, the National Endowment for the Humanities, and private sources, the Center has evolved into a full-service treatment facility for preservation of research materials. Another center is the Mid-Atlantic Preservation Service, based at Lehigh University. Each of these options has its limitations.

Some commercial facilities that have traditionally provided filming services mainly for business records have developed or are developing new services to film brittle books for libraries to exacting archival standards. In this regard, considerable ef- 
fort has been made from California to Virginia by individual librarians and library associations to educate people operating such commercial facilities about the special requirements for the filming of brittle books, as well as educating librarians as potential customers of such services to the information filmers need from them.

By way of example, I would like to note that the Association of Research Libraries, in partnership with NEDCC and with funding from the Andrew W. Mellon Foundation and the National Historical Publications and Records Commission, has developed a comprehensive instructional manual to assist in preservation microfilming. We expect publication of the manual by the American Library Association this year.

The majority of libraries will seek services outside their own organization to treat their brittle books. They will require many of the same things as libraries with an in-house program:

- Staff trained to assess the extent of the "brittle book problem" in a library collection, to develop a strategy for addressing the problem, and to coordinate the work.

- An internal process to identify, insure completeness of and prioritize the material needing treatment, within the context of a national strategy.

- Management support, e.g. operational models, guidelines, instructions, manuals, public information programs and staff workshops for continuing education.

- Bibliographic information within a national network to determine whether the brittle materials in library collections are unique, whether the item has already been reformatted and the microfilm available, or whether the item has been selected for filming but not yet treated elsewhere. (As noted elsewhere in my statement, the availability of such bibliographic information is absolutely essential for using our limited resources most effectively.)

-Funding to support staff to identify brittle materials that require reformatting and to pay for archival preservation filming, entering of the revised bibliographic data into a national database, and storage locally or elsewhere of the archival master file under archival conditions.

Libraries without in-house preservation facilities have one urgent need, however: more regional and cooperative centers. The number is slowly growing but most of the country is still unserved in this regard. Encouragement as well as financial support is necessary.

A survey of scholars by the National Humanities Alliance revealed that their high priority in the area of humanities scholarship was the preservation of research library material. Members of the American Library Association and the Association of Research Libraries have been aware of this crucial need. It was therefore most welcome news in 1985 when the National Endowment for the Humanities expanded its response to this national need by establishing the Office of Preservation. I could hardly exaggerate how important this NEH Preservation Program will be to libraries, though the funding has yet been much too small. Grants available from the Department of Education under the Higher Education Act, Title II-C, constitute another source of funding of extreme importance to a national preservation effort. Fortunately foundations such as the Andrew W. Mellon Foundation have also provided significant support. The State of New York has budgeted an exemplary statewide preservation program, and individual libraries have also built into their basic operating budgets a substantial commitment of financial resources.

As examples, some college and a few university libraries have found that they could commit $1 \%$ to $3 \%$ of their operating monies to their preservation effort. A substantial number of ARL libraries have made major efforts to increase this and are now committing $3 \%$ to $5 \%$ of their budget. A few libraries, all too few, have been able to budget as much as $6 \%$ to $8 \%$ of their total expenditures for preservation activities. The very significant effort libraries have made to address this problem is clear when a comparison is made between the amounts they have spent on preservation activities and the amounts spent on acquisition of new materials for the collection. From $10 \%$ to $25 \%$ of their entire materials budget is spent for binding, microfilming, or other preservation treatment. This can be regarded as a measure of the problem, the urgency with which the need is viewed by the administrations of these libraries.

One might ask how priorities can be set when libraries are able to spend limited sums on the preservation of materials and yet the problem is of awesome dimension. Let me cite a hypothetical example, based on a program designed for the Association of Research Libraries. ARL has used a documentary conspectus to provide a descriptive map of the strength of existing collections and current collecting efforts in specific subject fields. That data could provide the basis for selecting which members of ARL could best be asked to undertake preservation responsibility in this or that subject. Since library collections are not duplicates, two or even three libraries may need to pool their resources for adequate coverage of one subject. That sum of archival microfilm will then function as the representative collection of record for that subject field.

The Research Libraries Group of institutions has followed the same strategy. (RLG is a Connecticut corporation formed and supported by about three dozen research universities and libraries, with services used by many libraries scattered from Maryland and Florida to Colorado and California.) One of its long-standing programs is dedicated to the preservation of research library materials. Its members, nearly all of whom are also members of the American Library Association and the Associa- 


\section{IT WOULD TAKE YOU AROUND \\ four minutes to boil this egg}

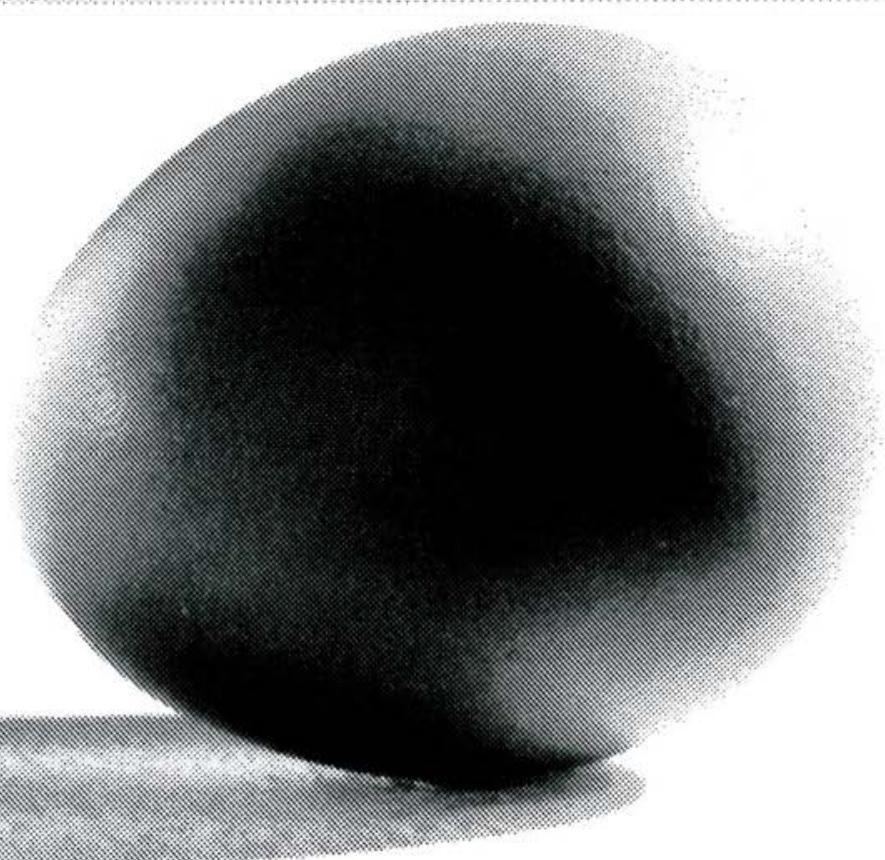

\section{IT WOULD TAKE YOU AROUND \\ sixty seconds to access \\ our million title database}

via our L/BTEL system

So why make a meal out of acquiring British academic books?

John Menzies has the perfect recipe. We're based in England and have a database of over 1,000,000 British titles. It takes just 60 seconds to access this database via our LIBTEL system which is available 24 hours a day for the cost of a local telephone call.

LIBTEL provides:

$\square$ Enquiry and pre-order verification on over 1,000,000 British titles.

$\square$ On-line ordering.

$\square$ Hard copy order confirmation and reporting.

We believe that we're faster, more competitive and more reliable than whoever you're currently dealing with and our complete range of Library Services includes:

$\square$ Comprehensive new title forms service.

$\square$ Subject listings - new and back list titles from our database.

$\square$ Fully automated Periodicals and Continuations subscription service. John Menzies have been active in book selling since 1833. Today we're part of an international Library Supply Network. Our associates include Coutts Library Services and Readmore in North America as well as Bennetts in Australia.

We're well established, efficient, fast and dependable. We don't just deliver the goods. We deliver the goods quickly. Check us out and see.

To obtain your LIBTEL access code or more information get in touch with Mike Dyche or Jo Buxton in Nottingham now - by phone (collect), Telex, Fax or Electronic Mail.

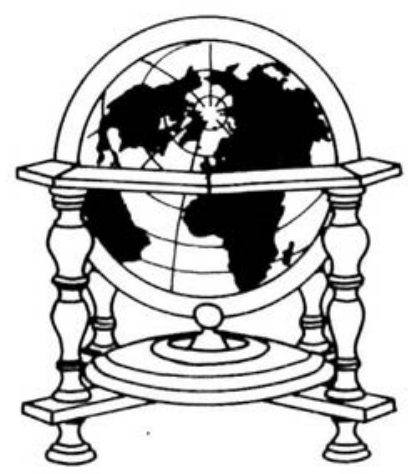

MENZIES

24 Gamble Street Nottingham

NG7 4FJ

England

PH: 602708021

TWX: 37577

JMLSNG G

FAX: 602787718

Electronic mail

OCLC DX: MNZ

W.L.N: MENZ 
tion of Research Libraries, have for four years been pursuing a focused and carefully worked out program of preservation microfilming. A conspectus of comparative collection strengths has been assembled. Libraries with special strength in a discrete subject field have undertaken filming of those items, concentrating first on U.S. imprints between 1850 and 1920. A computer database records decisions to film and lists resultant master films. Masters are stored archivally by a Pennsylvanian commercial firm. A broader cooperative attack on a similar prioritization basis, extended to foreign imprints and more recent publications, is now being fashioned by RLG. For an example, Chinese language materials of 1880-1949 are now being filmed.

While national standards would be used for a national program of preservation filming, the processes and priorities used to identify items for preservation would be left to the discretion of subject experts in the individual institution. In the interest of cost-effectiveness, all variants of a popular history or text would not be filmed, though all variant editions of a literary work would be. Also excluded would be, e.g., offprints and facsimiles. Within the subject designation assigned to a particular library, funds would be used to concentrate on the materials identified as being in the most brittle or physically deteriorated state. Once preservation copies have been made of those that are most endangered, one would then turn to those that will be in a similar state in another five or ten years, and so on in a progressive conversion effort.

The need to preserve representative rather than exhaustive collections for all subject areas requires that scholars and librarians plan within a national context and use limited resources in a coordinated fashion. Thus a "national collection" consisting of individual collections of discrete subjects at different institutions will be formed with minimal duplication and with future access assured for everyone. Later there may be the chance to supplement that national collection where other libraries can fill in significant gaps. But only in this systematic way can we guarantee that a balanced national collection of materials in all subject fields will be available in the next century.

I do not mean to suggest that all of the procedures and methods have been agreed to; quite the contrary. Yet the objective is universally supported. The standards are well understood. The dependability of preservation microfilming is well established. The longtime value of this investment is assured by storage of the master negative in secure vault-like quarters with suitable atmospheric conditions.

As the ARL testified in March 1986 before the House Subcommittee on Appropriations for the Interior Department and Related Agencies (including funding for the National Endowment for the Humanities), libraries also recognize an absolute requirement for a national bibliographic record, or catalog, which records when the preservation copy has been made, where it exists, and thereby publicly records where use copies may be purchased or borrowed. "Given the enormous amount of material to be preserved, the urgency to move ahead as quickly as possible, and the limited funding available, duplication must be avoided. Technology provides a reasonable solution: register local decisions to preserve a book, newspaper or any research material in a widely available database to alert others that the title need not be treated elsewhere and that the title is, or will be, available for use. Reasonable access to information about what titles have already been preserved or identified for treatment is a basic element of the infrastructure necessary to move this national objective ahead in a cooperative and expeditious manner. In short, we require a basic bibliographic structure in place to make wise preservation decisions."

Since that hearing, I am very pleased to report that the Mellon Foundation and NEH have awarded the Association of Research Libraries $\$ 1,200,000$ in funds to convert all monographic records in the National Register of Microform Masters (located in the Library of Congress) into a machine readable database, one that will be available two years from now in the RLG database, the OCLC database, the Western Library Network database and others. This project will be a grand achievement, providing a basic building block for the national bibliographic network necessary for economical preservation of brittle books.

Since we know the magnitude of the problem and since we have a methodology for selecting how and where to begin our attack, it is apparent that a solution to the problem is at hand if we act together. Let me add to its solution by providing the answers to three other key questions.

1. What are the appropriate Federal, State and private sector roles in efforts to address this problem? Each sector plays a key role, as I have suggested in the picture described above. Essential cooperative planning is provided by such organizations as ALA, ARL, RLG and the Council on Library Resources. The new National Commission on Preservation and Access can play a lead role. The Library of Congress has for years done us all a great service with its research and development work and its publicizing and proselytizing of the state of the preservation art-including international coordination work. The National Agricultural Library and the National Library of Medicine have also initiated preservation programs of value nationally and internationally. The Government Printing Office should be encouraged to work with librarians, archivists and paper companies to establish and apply standards for acid-free paper and binding as appropriate for a good part of government publications. The Higher Education Act Title II-C program and the National Historical Publications and Records Commission program are modestly funded but make significant contri- 
butions to the national preservation strategies. The program of the Office of Preservation in the National Endowment for the Humanities should be greatly strengthened.

2. What procedures are necessary to ensure public access to preserved materials? Part of the answer is easy, since public, academic and independent research libraries have a long-standing commitment to access. In addition, it requires that individual institutions, professional associations and funding agencies insist that bibliographic data be currently maintained on what is in the queue for filming, what has been completed and by whom. It requires that reading copies of the master films be readily available and publicized, and that the interlibrary services staff and users consider films as routine rather than exceptional loans. There is a role here for ALA, ARL, and consortia such as RLG.

3. And what are the costs and who should bear them? The Council on Library Resources has made fair estimates of the total cost. The total effort we face is daunting, perhaps on the order of tens of millions of dollars. While each group might like some other to pay full costs, that is patently unrealistic. A consensus exists among libraries that costs must be shared; some costs must be covered locally. Start up costs in particular need government and foundation help. Ongoing costs require local budgeting for at least a significant share, with endowment support for preservation programs in research libraries to the extent possible.
Yet one must recognize that libraries generally are so meagerly financed that there is little budgetary potential for dealing with problems of ten or fifty years hence when current book budgets and clientele services are severely beleaguered. The brittle books problem is a national concern, and indeed worldwide. Recognizing that, Federal support for a few decades is essential. A major share of start up costs should be a Federal responsibility, as should a strong portion of local operating costs.

Just as the Federal highway system is financed as being in the nation's interest, for both civilian and national defense purposes, exactly so should the "brittle books" system be financed as in the nation's interest: Students, scholars, our defense structure, our very civilization demands no less protection against the now recognized seeds of cultural destruction.

Thus it seems evident that there must be a Federal role, sharing the effort with state, local and institutional authorities.

Resolutions supporting a second White House Conference on Library and Information Services for 1989 have been introduced in the House and the Senate (H.J. Res. 90 and S.J. Res. 26). I call attention to this proposal on this occasion because we anticipate such a forum could provide an opportunity to focus national attention on the catastrophic consequences of the deterioration of printed material in the nation's libraries. As this hearing demonstrates, Congress is aware of the problem and is ac-

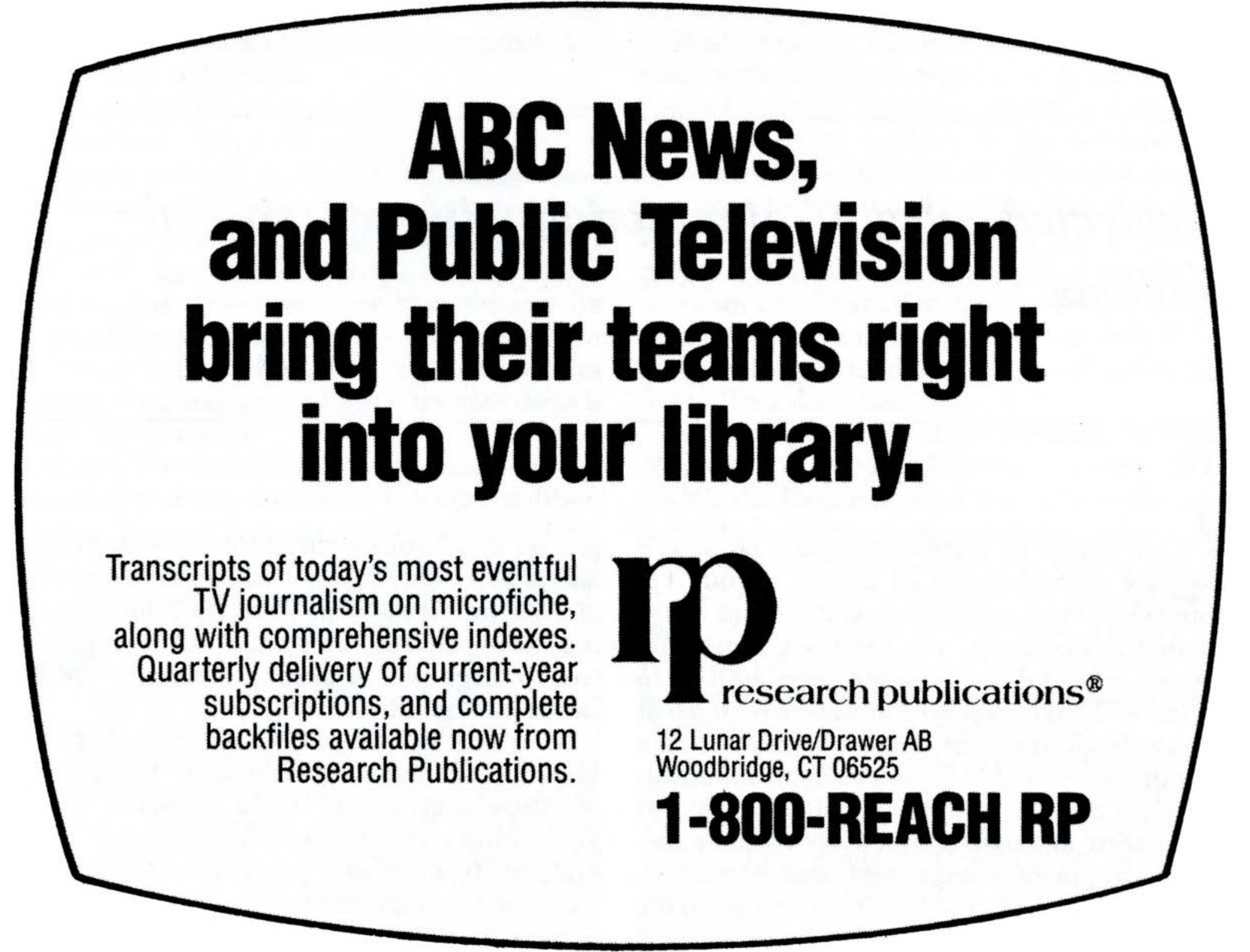


tively engaged in defining an appropriate federal role to contribute toward a solution. But we all acknowledge that Congress cannot solve the problem alone-nor can any other single agent. The enormity of the problem and the costs associated with developing and implementing programs to preserve brittle books dictate a responsibility within every sector of the nation. Therefore, while the proposed White House Conference on Library and Information Services will not "solve" the brittle book problem we consider here today, it would provide a forum to continue to raise the level of understanding about the scope and seriousness of the challenge we all face. We appreciate the support members of the Subcommittee showed in the past for the Conference and hope we may count on that support continuing again this year.
To sum up: We recognize the urgency and magnitude of the library materials preservation problem. We have a plan whereby decisions can be made as to what material needs preservation and in what priority. We have a rough idea of the costs involved. We accept the concept of reasonable cost sharing. And we are rather well equipped - except for the lack of a federal policy of commitment to help resolve the problem of brittle library materials, and except for sufficient funding.

To improve access to cultural resources and safeguard our own future, the Congress must act, providing leadership and help with financial aid. On behalf of the Association of Research Libraries and the American Library Association, I request your support.

\title{
Stalking the elusive grey literature
}

\author{
By Peter Allison \\ Head, Tamiment Institute Library \\ New York University
}

\section{A neglected category of materials with very special problems.}

\begin{abstract}
W e call it grey or fugitive literature because it eludes easy definition. It's all around us, but it is seldom central to our concerns as librarians or information professionals. You can't buy it in bookstores and most of it isn't marketed very actively to libraries. Although most grey literature is aimed at a non-academic audience, there is an active strain of grey literature within the scholarly communication process. Special libraries have always collected grey literature and used it effectively within a mediated environment. Larger, centralized academic libraries have found it problematic. Changes in the reward system within higher education and
\end{abstract}

greater emphasis on the training of professionals and practitioners have increased interest in this sort of material. At the same time, traditional solutions that have provided access and bibliographic control to large bodies of grey literature are being called into question.

Most grey literature does not contribute to the growth of fundamental knowledge. It applies existing knowledge to real world problems. It digests and summarizes knowledge for busy decision makers. It advocates particular policy choices based on a combination of knowledge and group interest. It advertises the accomplishments, collec- 